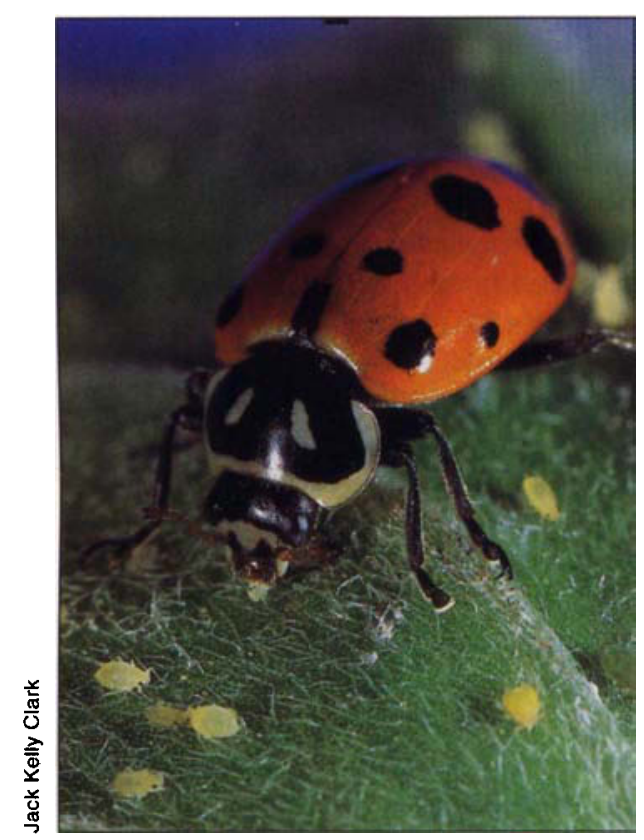

An adult Hippodamia convergens feeds on a melon aphid.

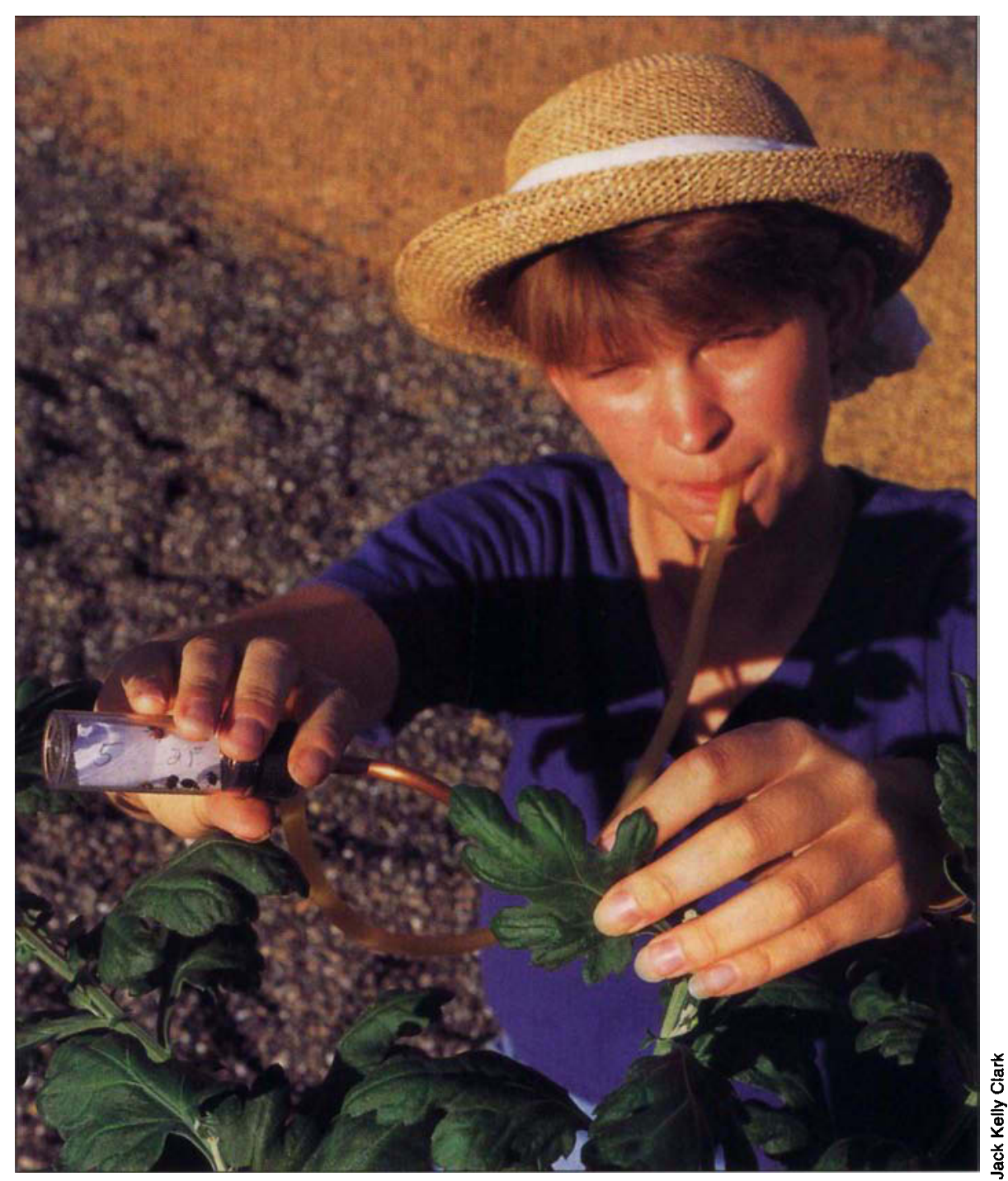

Jill Rentner samples lady beetles on a chrysanthemum plant.

\title{
Lady beetle release controls aphids on potted plants
}

\author{
Mary Louise Flint $\square$ Steve H. Dreistadt $\square$ Jill Rentner $\square \quad$ Michael P. Parrella
}

\author{
Releases of convergent lady \\ beetles collected in mountain \\ aggregations significantly \\ reduced aphid numbers on \\ chrysanthemum and rose plants \\ in pots. Preflying the beetles \\ before release, or rearing them in \\ a laboratory, did not clearly \\ reduce dispersal. Because of their \\ sensitivity to insecticides, care \\ must be taken when releasing \\ lady beetles into treated \\ environments.
}

The convergent lady beetle, Hippodamia convergens (Coleoptera:

Coccinellidae) is the least expensive and most widely released aphid predator in the United States. This lady beetle is unusual because a large portion of its California population migrates to the mountain ranges when aphid populations in the Central Valley drop in summer. The beetles spend the winter in massive mountain aggregations, taking in water but consuming no aphids, and fly back down to the valley in March when the tempera- ture warms up (fig. 1). This aggregating habit allows collectors to harvest and package large numbers of convergent lady beetles for sale in nurseries and through garden supply catalogs and other outlets across the country.

Despite widespread use, the University of California has historically recommended against releasing aggregation-collected $H$. convergens because they were believed to require a substantial flight (normally acquired when they return to the valley in the spring) before they will consume sig. 


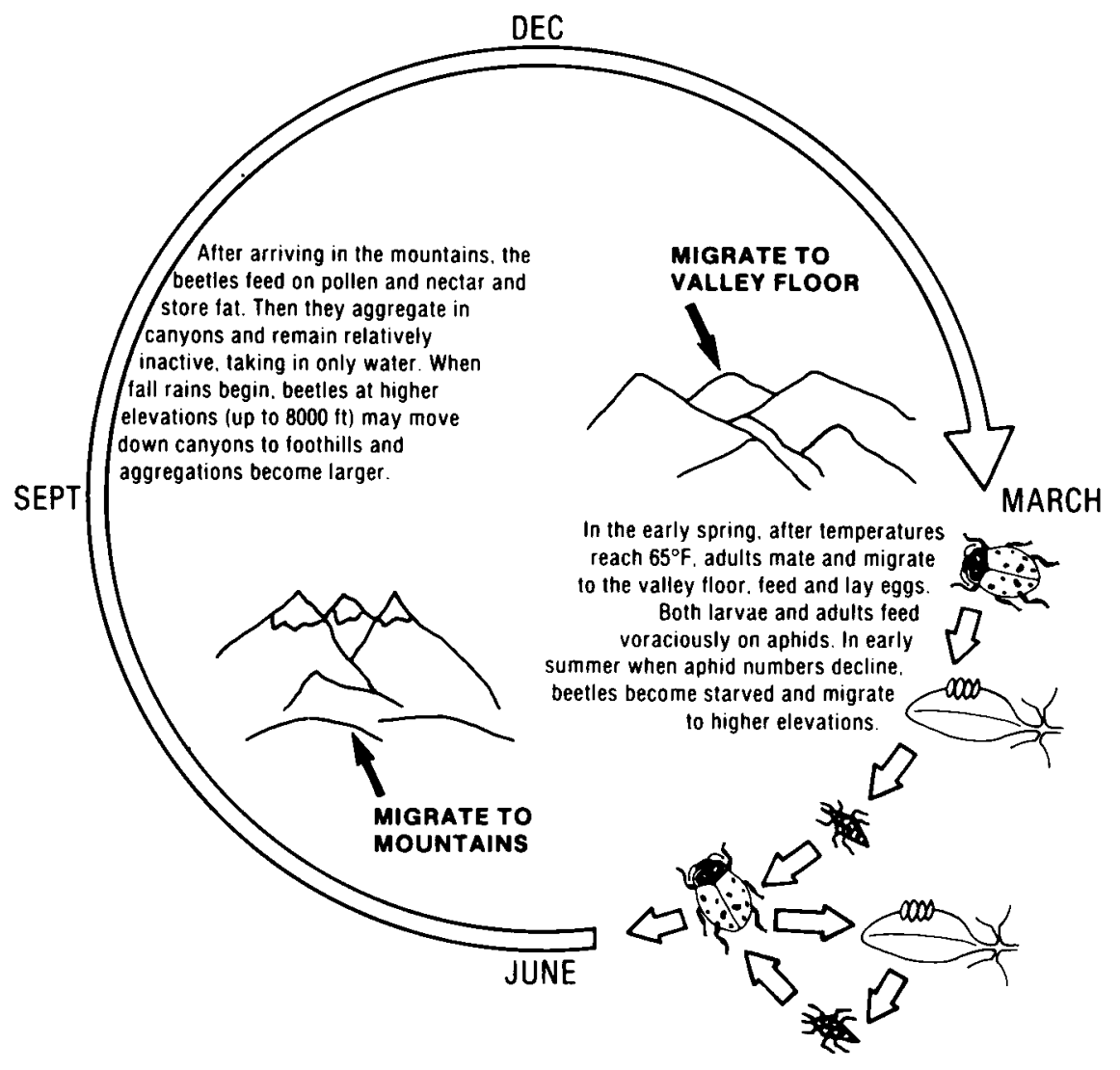

Fig. 1. The annual cycle of convergent lady beetle migration and aggregation in California allows collectors to harvest large numbers for sale with minimal effort. From UC ANR Publication 3312, Integrated Pest Management for Alfalfa Hay.

nificant numbers of aphids. Therefore it was believed that releases of aggregation-collected lady beetles would not be effective because they would disperse before feeding on aphids. However, these recommendations were based mostly on field observations made in the 1910s and 1920s rather than on replicated field trials. Some lady beetle suppliers suggest that preflying beetles before release increases retention, but no research had been carried out to verify this claim.

The purpose of our research was to determine (1) if preflying aggregationcollected lady beetles decreases their tendency to fly away; (2) if laboratoryreared lady beetles are less likely to fly away than aggregation-collected ones; (3) if lady beetle releases can control aphid populations; and (4) the impact on lady beetle survival of insecticides commonly used on ornamental plants.

\section{Preflying lady beetles}

We used mark-release-recapture experiments to test the hypothesis that preflying lady beetles collected in mountain aggregations would reduce their dispersal. In this and subsequent studies we released beetles on potted roses (Rosa sp.) infested with rose aphids (Macrosiphum rosae) and on potted chrysanthemums (Dendranthema grandiflora) infested with melon aphids (Aphis gossypii). All experiments were conducted outdoors on a gravel surface at the UC Davis Arboretum holding area with lady beetles collected from the same aggregation site in Placer County, California by a commercial lady beetle supplier.

Prior to release, adult lady beetles from aggregations were either removed from cold storage $\left(40^{\circ}\right.$ to $\left.50^{\circ} \mathrm{F}\right)$, allowed to fly outdoors for 1 week in a 10-feet-by-10-feet-by-8-feet, screenwall cage, and sprayed daily with diluted honey (flown); or removed from cold storage about 8 hours before release, confined with honey and water, and sprayed with $7 \mathrm{Up}$ soda, as recommended by some lady beetle suppliers, immediately after release (stored).
Beetles were marked with lacquer to distinguish treatments, and 14 to 20 beetles from each treatment were released per pot once at dusk on groups of five or six pots. Each pot contained either four chrysanthemum plants or one rose plant. Each group of pots was replicated six to eight times in a randomized block design and separated from other groups by 10 meters of gravel surface. Every 12 to 24 hours for 3 or 4 days after release, beetles were collected and counted on plants in one or more previously unsampled pots from each replicate (fig. 2). This experiment was conducted on chrysanthemums in May, July and September of 1993 with beetles collected from winter, early summer and late summer aggregations respectively, and was conducted once in April on roses.

A large portion of both stored and flown lady beetles dispersed from plants within the first 24 hours. More flown than stored beetles were recovered on chrysanthemums at 9 of 13 postrelease sample times, but differences were statistically significant in only three instances, twice when more flown beetles were recovered and once when more stored beetles were recovered (fig. 2). In the one rose trial, significantly more stored than flown beetles were recovered 12 hours after release $(P<0.05, \mathrm{t}$-test $)$. More flown

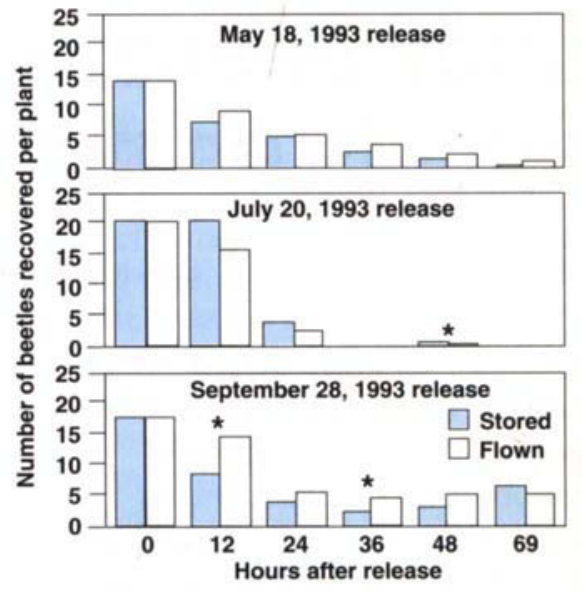

Fig. 2. Number of Hippodamia convergens adults recovered at intervals after a single release outdoors on potted chrysanthemums infested with Aphis gossypii. Number of beetles at 0 hours indicates number of beetles released. *Recovery of flown and stored beetles was significantly different $(P<0.05)$ on only 3 of 13 postrelease sample dates. 
beetles were present at the next 5 sample times, but the difference was significant only at 36 hours after beetle release ( $P<0.05$, t-test).

These data suggest no strong effect of preflying, but larger-scale trials are needed to confidently determine whether allowing beetles to feed and fly prior to release can reduce their dispersal. Clearly, preflying requires considerable extra effort and expense, which may not be justified by a marginal increase in retention.

\section{Dispersal tendency}

Although aggregation-collected lady beetles were believed to require a substantial flight period before settling down to feed on aphids, it has been suggested that later generations of lady beetles, reproducing in the Central Valley without long-range flight to the mountains, have less tendency to fly. For this reason there has been some interest in rearing $H$. convergens in insectaries to produce commercially available, nondispersing lady beetles for mass release.

To compare the dispersal tendencies of aggregation-collected versus

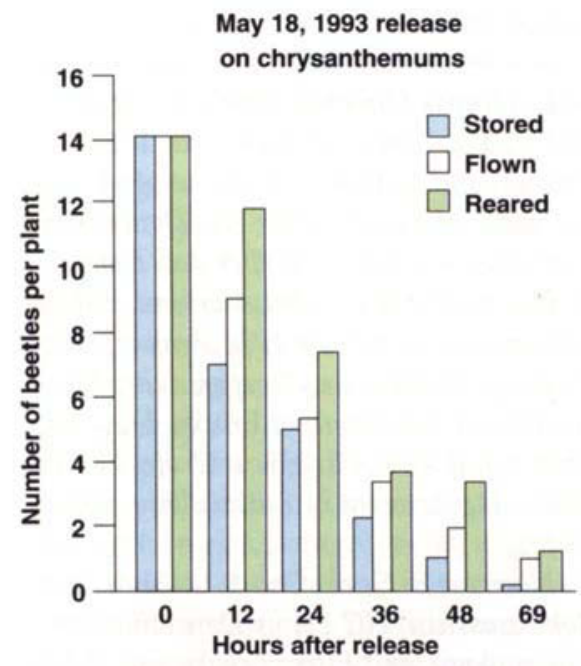

Fig. 3. Number of Hippodamia convergens adults recovered at intervals after a single release outdoors on potted chrysanthemums infested with Aphis gossypii. Number of beetles at 0 hours indicates number of beetles released. There was no significant difference $(P>0.05$ t-tests) in the number of beetles recovered at any sample time between reared, flown or stored beetles except at 48 hours when significantly more flown than stored beetles were recovered $(P=.05)$.

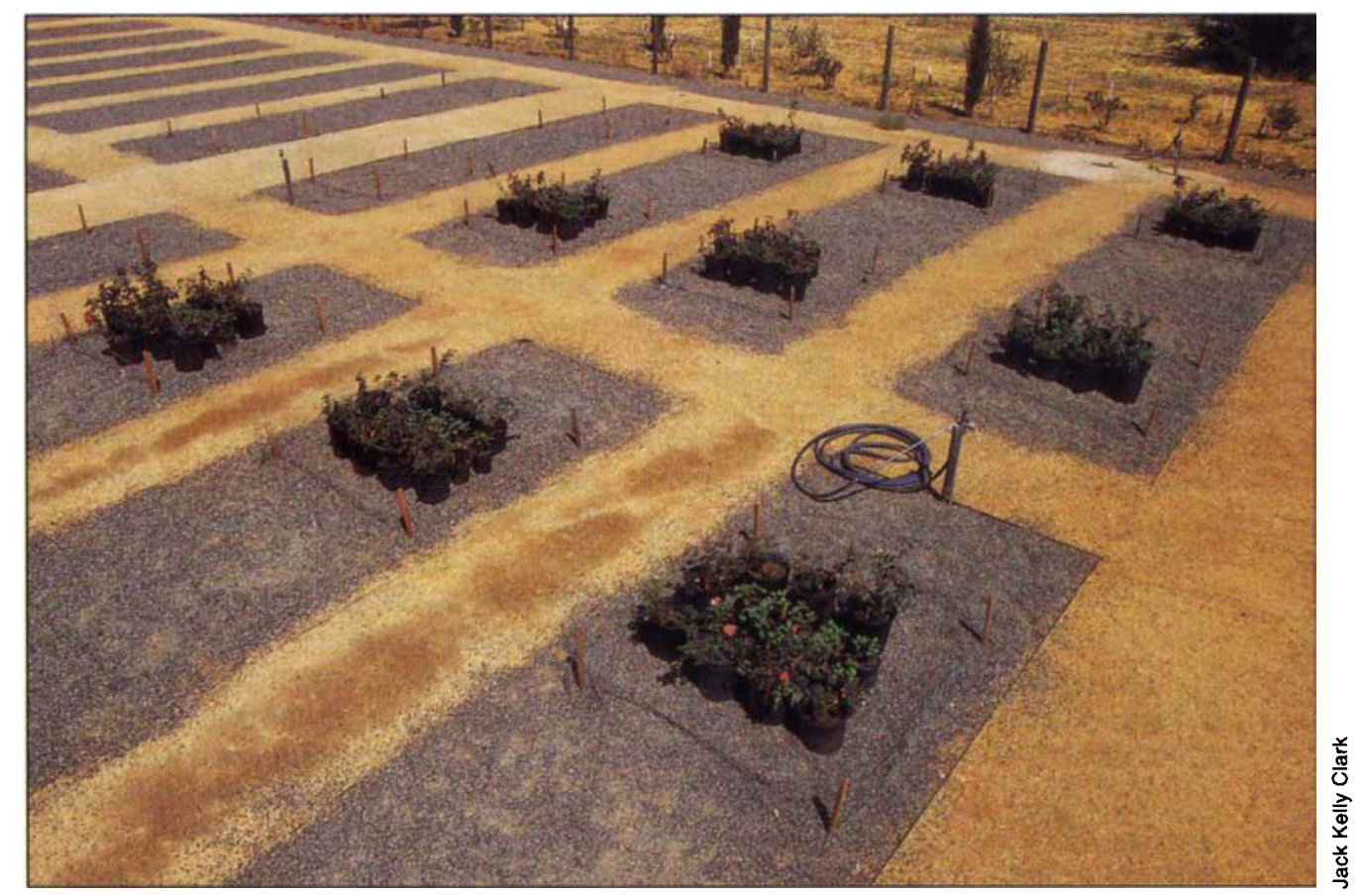

Aggregation-collected and laboratory-reared lady beetles were released into experimental plots of aphid-infested roses and chrysanthemums. The lady beetles significantly reduced the numbers of aphids.

laboratory-reared lady beetles, we conducted a mark-release-recapture study during May of 1993 on melon aphid-infested potted chrysanthemums, following the basic procedures just described for preflying. We made one release at dusk of lady beetles that were either first-generation offspring of lady beetles collected in a Davis alfalfa field and reared in the laboratory on aphids (reared); or aggregationcollected lady beetles that were flown (flown); or aggregation-collected beetles 8 hours after removal from the refrigerator (stored). Fourteen beetles from each treatment were released at the base of the plants in each pot, pots were placed in groups of five, and each group was replicated six times. Every 12 to 24 hours for 3.5 days after release, beetles were collected and counted on plants in one previously unsampled pot from each replicate.

Differences between treatments were not clear cut. Almost half of the reared beetles dispersed within 24 hours. Although reared beetles showed less tendency to disperse, there were no statistically significant differences between retention of stored, flown and reared beetles at any sample times in this experiment except

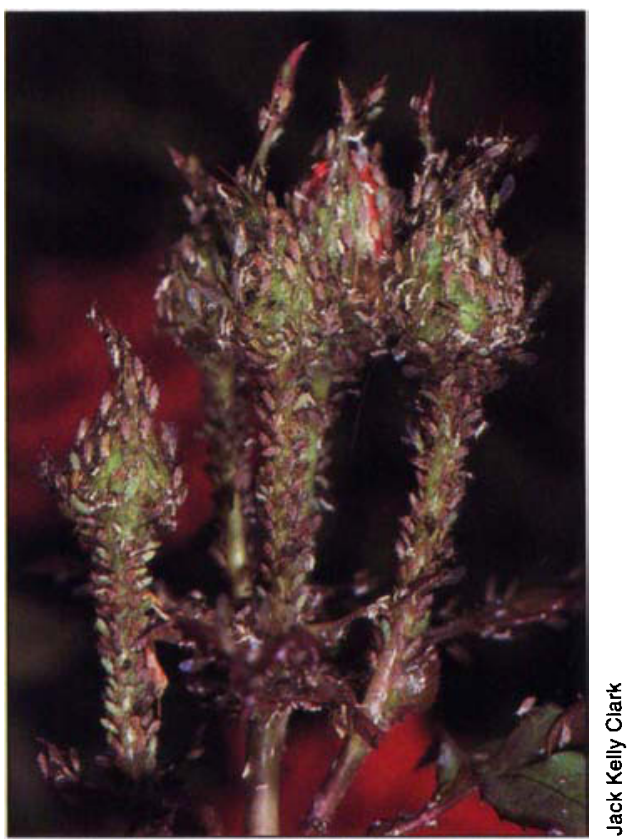

Rose aphid populations increased on rose buds in control plots, but fell significantly where lady beetles were released onto potted rose shrubs.

at 48 hours (fig. 3). Small differences in dispersal are likely to be of little practical value, given the substantial effort and cost needed to rear lady beetles compared to the inexpensive, easily collected aggregation beetles. For a 


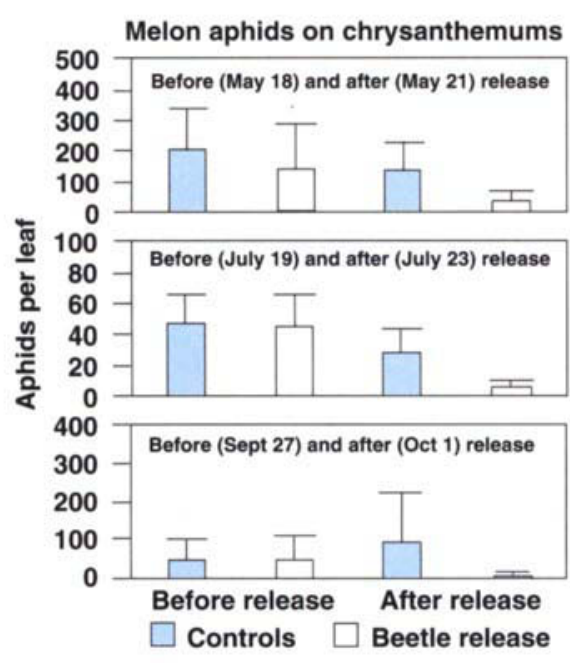

Fig. 4. Mean (+SD) melon aphid densities before and 3 days after release of 34 to 42 adult lady beetles per pot outdoors on chrysanthemums. Prior to beetle release, there were no differences in melon aphid densities between release and control plants $(P>0.001$, t-tests). Three days after releasing lady beetles, aphids were signifjcantly less abundant on release plants in comparison with controls in all three trials $(P<0.001$, t-tests).

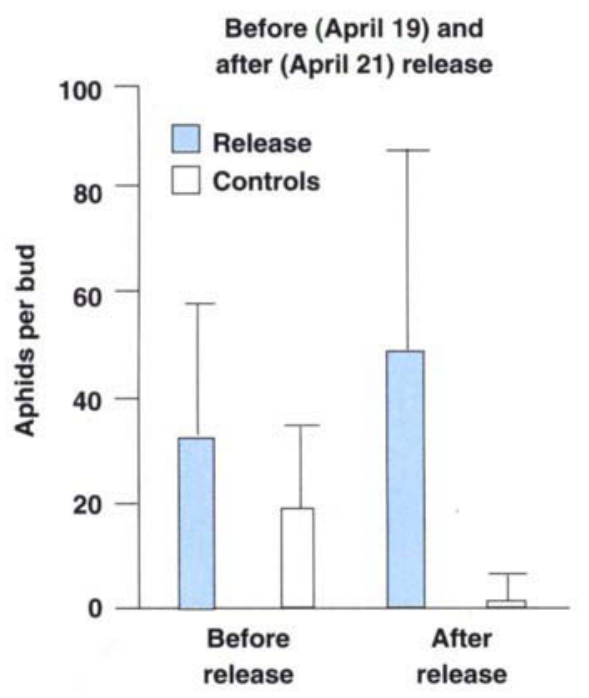

Fig. 5. Mean (+SD) rose aphid densities before and 3 days after a single release of 60 adult lady beetles per potted shrub. Prerelease rose aphid densities were greater on controls than on release plants $(P<0.01$, t-test $)$, but differences were not significant at the $P>0.001$ level. Three days after releasing lady beetles, aphids were significantly less abundant $(P<$ 0.001 , $t$-test) on release plants in comparison with controls.

very rough comparison, consider that a gallon of lady beetles, containing approximately 80,000 beetles, can be purchased for about $\$ 40$; whereas a laboratory-reared mealybug destroyer lady beetle, Cryptolaemus montrouzieri, costs approximately 10 cents per beetle, or about 200 times as much.

\section{Reduction in aphid populations}

To determine if releases of $H$. convergens would control aphids, we compared aphid populations on release and nonrelease plants. Lady beetles were released once and sampled as described above on groups of aphid-infested potted chrysanthemums or roses. Figures 2 and 3 show numbers of lady beetles released on each trial date. For controls, no releases were made on one to four groups each of five to eight pots of aphid-infested plants. For chrysanthemums, numbers of aphids were assessed by counting the total number on one middle leaf on each of the four plants in each pot before beetle release, and again 3 days after release. For roses, numbers of aphids were assessed by counting numbers on unopened flower buds (with an average 3.5 buds per plant) before beetle release and again 3 days after release. Both of these sample units are based on previous research on these pests.

Lady beetle releases in all four trials (three chrysanthemum, one rose) significantly reduced aphid numbers compared to controls (figs. 4 and 5). A portion of the released lady beetles remained on infested plants, apparently feeding on aphids, until our final sample 3 days after release.

\section{Impact of insecticide residues}

If lady beetle releases are to be used in an integrated pest management program that includes insecticide applications for other pests, it is critical to know the impact of insecticide materials on lady beetles. In research not detailed here, we evaluated the effects of leaf residues of five common insecticides used on ornamental plants and found that residues of malathion and carbaryl on normally weathered foliage outdoors can kill newly exposed lady beetle adults for up to 2 weeks after application. In contrast, dried residues of insecticidal soap or oil had no effect 1 hour after treatment. Pyrenone residues had little or no effect after 1 day. Our methods represented "worst case" mortality from these materials because beetles were confined with leaves in containers and exposed through a combination of ingestion, contact and inhalation. However, these results illustrate the need to consider the impact of previous pesticide treatments before releasing lady beetles for control.

\section{Conclusions}

Releases of aggregation-collected Hippodamia convergens significantly reduced populations of melon aphids on potted chrysanthemums and of rose aphids on potted roses. Our results apply only to small potted plants. We are not aware of any studies showing that lady beetle releases are effective on a large scale. Most beetles left the plants within 1 or 2 days of release. Allowing beetles to fly and feed before releasing them, or releasing laboratory-reared beetles instead of aggregation-collected beetles from cold storage, may reduce dispersal, but this is uncertain and requires more research; the economic return of such treatments needs to be examined carefully. If lady beetle releases are made in conjunction with insecticide sprays for other pests, substantial care should be taken in the choice of material to avoid killing released beetles.

M.L. Flint is Director, IPM Education and Publications, UC Statewide IPM Project, and Extension Entomologist, Department of Entomology, UC Davis; S.H. Dreistadt is a Senior Writer and Entomologist with IPM Education and Publications, UC Statewide IPM Project, UC Davis; J. Rentner was Postgraduate Researcher, Department of Entomology, UC Davis; and M.P. Parrella is Professor and Chair, Department of Entomology, UC Davis.

Norman E. Gary, Chuck LeGault, and Bob Rousseau, UC Davis Department of Entomology, and Ellen Zagory and Robin Rosetta, UC Davis Arboretum, assisted us. Kenneth Hagen, UC Berkeley and Lester Ehler, UC Davis Department of Entomology provided helpful review comments. The UC Slosson Fund Endowment for Ornamental Horticulture provided financial support. Unique Insect Control, Citrus Heights, California, provided the lady beetles. Roses were provided by Bear Creek Gardens, Medford, Oregon. 